\title{
BM] Global Health The information problem in global health
}

Seye Abimbola

To cite: Abimbola S. The information problem in global health. BMJ Global Health 2016;1:e900001. doi:10.1136/bmjgh-2015900001

\section{CrossMark}

Editor-in-Chief, BMJ Global Health, School of Public Health, University of Sydney, Australia.

Correspondence to Seye Abimbola; seyeabimbola@hotmail.com
One of the many things that the global health community is in agreement about is that we really do not know how to define global health - and this is not for want of attempts. ${ }^{1,2}$ My favourite characterisation so far is the description of global health as 'a collection of problems rather than a discipline'; a collection of problems which 'turn on the quest for equity'; equity in health indices within and between the national boundaries of high, middle or low-income countries. ${ }^{3}$

These problems range from the challenge of addressing the recent Ebola outbreak in three West African countries, to the growing global burden of non-communicable diseases, eradicating polio or finding a cure to HIV/AIDS; and most important of all, ensuring that governments, non-government organisations, the private sector and communities are able to build and run health systems strong enough to facilitate these outcomes.

But with its focus on 'achieving equity in health for all people worldwide', ${ }^{2}$ global health is inherently and unavoidably paternalistic. ${ }^{4}$ Global health exists mostly to help someone else, and that comes with an information problem: ${ }^{5}$ the people in control of resources to address global health challenges often do not have adequate information to design and implement effective interventions in contexts far removed from their own realities. Likewise, the disadvantaged people who typically constitute the target of global health interventions also often do not have adequate information to help themselves.

This information problem is an important component of the collection of problems that make up global health. It is however a problem that is often not taken seriously enough. $^{6}$ This new journal - BMJ Global Health - seeks to address the information problem in global health by being a vibrant discussion forum; an open and inclusive forum that brings together and addresses the broad community of global health stakeholders.
An online-only Open Access journal, BMJ Global Health aims to help achieve a world in which every person and country has access to the information about health, health care and social determinants of health that they need to protect their own health and the health of the people for whom they take responsibility. We will publish content that is relevant to everyone involved in global health - global, national and sub-national policy makers, funders, researchers, clinicians and, crucially, frontline health care workers and managers.

BMJ Global Health will publish research and review papers, editorials and commentaries, and analysis and correspondence articles. We will welcome research in all genres, and in all study phases and designs. Recognising the multidisciplinary nature of research to improve global health, we will publish studies using social science methods and approaches, and also papers ranging from study protocols to phase I trials to meta-analyses. Our aim is to be a forum where different strands of evidence come together, where one form or scale of evidence is not privileged over another.

In line with this aspiration, BMJ Global Health will welcome opinionated discussions on controversial topics and will also feature long-form reporting about the health and health care of disadvantaged populations around the world wherever they are; whether in high, middle or low income countries. We will aim to be relevant, accessible and enjoyable, not only to researchers but also to the larger global health public.

BMJ Global Health will operate a fast, supportive and rigorous peer review process, and manuscripts will be considered based on ethical and methodological soundness rather than novelty, significance, or relevance to any particular group. However, we will particularly encourage and support health researchers and practitioners from low- and middle-income countries to publish their work, experiences and ideas in BMJ Global Health. 
Please join us in addressing the information problem in global health by engaging with the global health community through BMJ Global Health - as a regular reader, an author, and a peer reviewer; and no less important, by responding to published articles using the rapid response feature on our website, and by providing feedback to us on how to improve the journal.

\section{Twitter Follow Seye Abimbola at @seyeabimbola}

Open Access This is an Open Access article distributed in accordance with the Creative Commons Attribution Non Commercial (CC BY-NC 4.0) license, which permits others to distribute, remix, adapt, build upon this work noncommercially, and license their derivative works on different terms, provided the original work is properly cited and the use is non-commercial. See: http:// creativecommons.org/licenses/by-nc/4.0/

\section{REFERENCES}

1. Freeman P, Robbins A. An inquiry in the name of 'global health'. $J$ Public Health Policy. 2008;29:379-82.

2. Koplan JP, Bond TC, Merson MH, et al. Towards a common definition of global health. Lancet 2009;373:1993-5.

3. Farmer P. Preface. In Farmer P, Kim JY, Kleinman A, Basilico M, eds. Reimagining global health: an introduction. Berkeley: University of California Press, 2013.

4. Horton R. The case against global health. Lancet 2014;383:1705.

5. Gibson CC, Andersson K, Ostrom E, et al. The Samaritan's dilemma: the political economy of development aid. Oxford: Oxford University Press, 2005.

6. Smith R, Koehlmoos TP. Provision of health information for all. BMJ 2011;342:d4151. 